\title{
Genetic assessment of the Iberian wolf Canis lupus signatus captive breeding program
}

\author{
Oscar Ramirez ${ }^{1}$, Laura Altet ${ }^{1}$, Conrad Enseñat ${ }^{2}$, Carles Vilà ${ }^{3}$, Armand Sanchez ${ }^{1} \&$ \\ Alfredo Ruiz ${ }^{4, *}$, \\ ${ }^{1}$ Departament de Ciència Animal i dels Aliments, Universitat Autònoma de Barcelona, Barcelona, Spain; \\ ${ }^{2}$ Parc Zoologic de Barcelona, Barcelona, Spain; ${ }^{3}$ Department of Evolutionary Biology, Uppsala University, \\ Uppsala, Sweden; ${ }^{4}$ Departament de Genètica i Microbiologia, Facultat de Ciències - Edifici C, Universitat \\ Autònoma de Barcelona, 08193, Bellaterra, Barcelona, Spain (*Corresponding author: E-mail: Alfredo. \\ Ruiz@uab.es)
}

Received 20 June 2005; accepted 20 January 2006

Key words: captive breeding, dog, genetic diversity, microsatellites, wolf

\begin{abstract}
The main goal of ex situ conservation programs is to improve the chances of long term survival of natural populations by founding and managing captive colonies that can serve as a source of individuals for future reintroductions or to reinforce existing populations. The degree in which a captive breeding program has captured the genetic diversity existing in the source wild population has seldom been evaluated. In this study we evaluate the genetic diversity in wild and captive populations of the Iberian wolf, Canis lupus signatus, in order to assess how much genetic diversity is being preserved in the ongoing ex situ conservation program for this subspecies. A sample of domestic dogs was also included in the analysis for comparison. Seventy-four wolves and $135 \mathrm{dogs}$ were genotyped at 13 unlinked microsatellite loci. The results show that genetic diversity in Iberian wolves is comparable in magnitude to that of other wild populations of gray wolf. Both the wild and the captive Iberian wolf populations have a similarly high genetic diversity indicating that no substantial loss of diversity has occurred in the captive-breeding program. The effective number of founders of the program was estimated as $\sim 16$, suggesting that all founders in the studbook pedigree were genetically independent. Our results emphasize also the genetic divergence between wolves and domestic dogs and indicate that our set of 13 microsatellite loci provide a powerful diagnostic test to distinguish wolves, dogs and their hybrids.
\end{abstract}

\section{Introduction}

During the last centuries, more than 300 vertebrate species have become extinct and the population sizes of many other have been so reduced as to consider them threatened species (Baillie et al. 2004). This has given rise to an increased awareness for the need of developing in situ and ex situ conservation programs. The aim of these programs is to improve the chances of long term survival of the natural populations. Ex situ programs require the founding and managing of captive colonies that can serve as a source of individuals for future reintroductions or to reinforce existing populations and have already shown their potential to rescue highly endangered species, like for the California condor (Gymnogyps californianus, Geyer et al. 1993) or the Przewalski's horse (Equus przewalskii, Bouman and Bouman 1994). In these cases only a handful of individuals survived in the wild when the captive breeding program started. However, in many cases the aim 
of the ex situ conservation programs goes beyond the survival of some individuals and their descendants, but targets the conservation of the genetic diversity over long periods. Genetic diversity is essential to ensure the conservation of the evolutionary potential that could allow the population to adapt to changing environments (Frankham et al. 2002).

Conservation of genetic diversity in a captive population is a difficult task. These populations are usually established by a very small number of individuals, which can lead to dramatic founding effects (Hedrick 2005). Additionally, the growth of the population is usually very restricted because of available infrastructures. This puts an upper bound to the size of the captive population, which translates into a small effective population size. In a random mating population, the portion of the heterozygosity that is lost every generation as a result of the random genetic drift is $1 /\left(2 N_{\mathrm{e}}\right)$, where $N_{\mathrm{e}}$ is the effective population size (Hedrick 2005). This means that a population with 10 contributing founders will retain initially $95 \%$ of the original heterozygosity and, if the population remains at this size, it will keep losing $5 \%$ of the heterozygosity every subsequent generation. On the other hand, a minimum of 30 founders are needed for a $95 \%$ probability of capturing an allele with a frequency of 0.05 in the source population (Frankham et al. 2002). Different management strategies can be implemented to minimize the loss of genetic diversity in captive populations (Ballou and Lacy 1995; Ballou and Foose 1996; Frankham et al. 2002; Russello and Amato 2004).

In spite of the importance to ensure its success, the degree in which a captive breeding program has captured the genetic diversity existing in the source wild population has seldom been evaluated (Wyner et al. 1999; Storme et al. 2004). In this study we evaluate the genetic diversity in wild and captive populations of the Iberian wolf in order to assess how much genetic diversity is being preserved in the ongoing ex situ conservation program.

The gray wolf had an extensive distribution covering Europe, Asia and North America, but as a result of the human persecution its populations have been fragmented and reduced across most of its range and especially across Europe (Boitani 2003). The largest population in Western Europe survived in the Iberian peninsula, where the total wolf population was estimated to be around 20002500 wolves in the early 1990s (Blanco et al. 1992). The Iberian wolf was identified as a separate subspecies, Canis lupus signatus, by Cabrera (1907). Although this subspecies is not commonly recognized (Nowak 2003; Sillero-Zubiri et al. 2004), a morphometric analysis (Vilà 1993) described differences in skull shape separating Iberian wolves from wolves in Italy and other populations in Eastern Europe. Additionally, mitochondrial DNA data and microsatellite frequencies showed a notable differentiation between Iberian wolves and those found elsewhere in Eurasia (Vilà et al. 1999; Lucchini et al. 2004). These two lines of evidence indicate that Iberian wolves have been separated from all other European wolves for a long time and demand a separate management, recognizing its evolutionary potential (Crandall et al. 2000).

As in the rest of Europe, the Iberian wolf was intensely hunted because of livestock depredation and the competition with humans for wild prey, resulting in a population decline during the 19th and 20th centuries (Enseñat 1996; Figure 1). Although in recent years the range of the Iberian wolf may have been expanding, isolated nuclei south of the Duero river may have disappeared (Alonso et al. 1999; however, see also Blanco and Cortés 2002) and have been declared of priority concern (Habitats Directive of the European Union). In 1994, the European Breeding of Endangered Species Programme (EEP) started a breeding program for the Iberian wolf with 40 animals (23 males and 17 females) distributed in 13 institutions. According to the studbook these animals derived from 15 founders. Currently the EEP population is composed of 51 wolves (27 males and 24 females) distributed in nine lineages (a lineage is a founder or pair of founders and all their descendants) (see Figure 2). Three of the lineages have a wild ancestry (the founders are wild animals), the origin of five other is unknown (the founders are captive Iberian wolves) and one has a mixed origin (one founder is a wild wolf and the other is a captive animal). Thus, although the number of founders in the studbook is 15 , some of them could have been related and the actual number of (genetically independent) founders for the EEP populations is not known.

In this study we have analyzed the microsatellite variability in the wild and captive population 


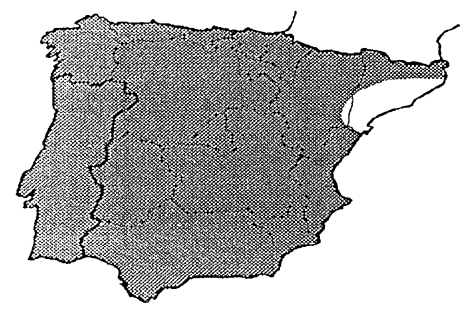

1840

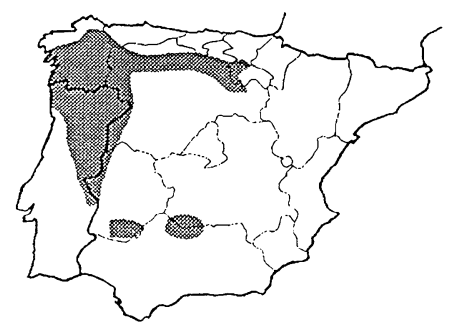

1975-80

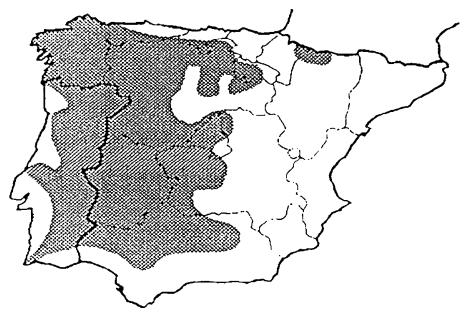

1940

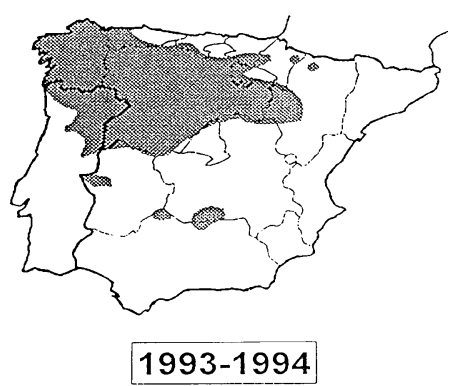

Figure 1. Historical reduction of the Iberian wolf geographical distribution in the Iberian Peninsula (Enseñat 1996).

of the Iberian wolf: (i) to provide an estimate of the amount of genetic variability in this subspecies; (ii) to compare the level of variability and differentiation between the EPP and the wild population in order to assess if the managed captive population is representative of the diversity existing in the wild and to assess its adequacy for a possible reintroduction; (iii) to study the relationships within the EEP population including animals with unknown ancestry and estimate the effective number of founders; (iv) to provide a system for individual identification and reliable parentage testing which allows us to optimize the genetic management of the EEP population; and (v) to assess the differentiation between wolves and dogs and determine the likelihood of detecting wolf-dog hybrids.

\section{Materials and methods}

\section{Samples}

Three samples, adding to a total of 74 Iberian wolves, were used for the present study. The first group (WILD) included 20 wild wolves captured in different Spanish provinces: Asturias (seven), Cantabria (four), Orense (one), Palencia (two), Pontevedra (one), Valladolid (one) and Zamora (four). The second group (EEP) was composed of

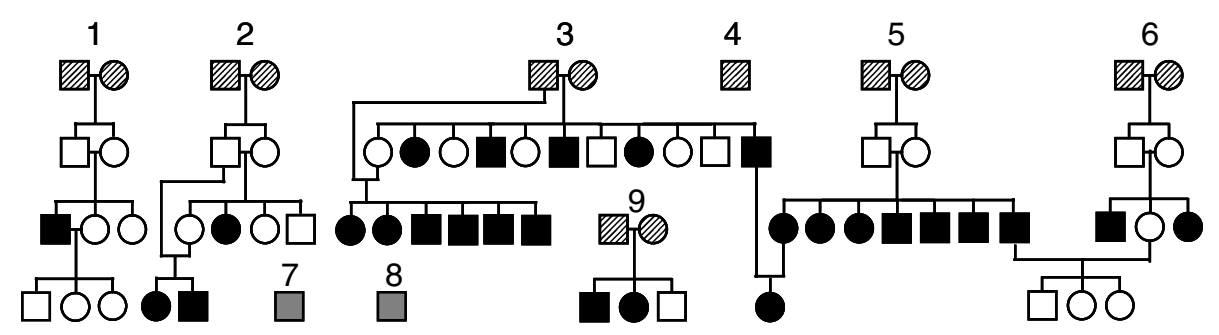

Figure 2. Pedigree of the EEP Iberian wolf population. The 15 founders are indicated by shaded (or gray) symbols. The pedigree comprises nine lineages (1 Cabárceno, 2 Madrid-1, 3 Maiztegui, 4 Rotterdam, 5 Jerez, 6 Biorama, 7 Guadalajara, 8 Madrid-2, 9 Santillana) and includes the 29 individuals analyzed in this study (solid or gray symbols). 
29 wolves from a total of 51 wolves included in the breeding program of the EEP. The EEP population comprises nine lineages (Figure 2). Three of theses lineages (Cabarceno, Madrid-2 and Santillana) have a wild ancestry. One of them (Maiztegui) has a mixed origin (one founder with wild ancestry and another one of unknown origin). The origin of the other five lineages is unknown. The 29 individuals of the EEP analyzed here belong to nine different institutions affiliated with the program (Barcelona, Cabárceno, Guadalajara, Jerez, Lisbon, Madrid, Santillana, Vergel and Vizcaya) and represent eight of the nine lineages present in the EEP population, all except Rotterdam (Figure 2). The third group (CAPTIVE) was composed of 25 captive wolves from 13 different institutions. This third sample includes animals that were already captive when the EEP program started in 1994 but, for different reasons, were not included in the captive breeding program. In addition, a sample of 135 unrelated domestic dogs provided by local breeders was also included in our study for comparative purposes. These dogs belong to 35 different breeds including the three autochthonous breeds (Spanish Mastiff, Pyrenean Mastiff and Pyrenean Mountain Dog) most used by Spanish shepherds to protect livestock.

\section{Microsatellite markers}

Genomic DNA from blood samples was isolated as described elsewhere (Francino et al. 1997). A total of 13 microsatellites were analyzed: eight dinucleotide markers CPH5 and CPH9 (Fredholm and Wintero 1995) and CXX366, CXX403, CXX 410, CXX442, CXX459 and CXX474 (Ostrander et al. 1995); and five tetranucleotide markers CXX2001, CXX2010, CXX2130, CXX2054 and CXX2158 (Francisco et al. 1996). The analyzed microsatellites are autosomal and unlinked, providing independent markers (Mellersh et al. 1997, 2000). Genomic DNA was amplified using two multiplex PCR reactions with seven markers in multiplex-1 (CPH5, CXX366, CXX2158, CPH9, CXX2130, CXX474 and CXX459) and six in multiplex-2 (CXX2001, CXX2010, CXX2054, CXX 403, CXX410 and CXX442). The two multiplex PCR reactions were carried out in $10 \mu$ l of final reaction mixture containing PCR buffer $(1 \times)$, $1.5 \mathrm{mM} \mathrm{MgCl} 2,0.2 \mathrm{mM}$ of each dNTP (PE Bio- system), $1 \mathrm{U}$ of $T a q$ polymerase (Life Technologies Inc.), and 30-40 ng of genomic DNA. Primer concentration was optimized for each marker: 0.2 $\mu \mathrm{M}$ for tetranucleotide markers, $0.3 \mu \mathrm{M}$ for $\mathrm{CPH} 5, \mathrm{CPH} 9$ and CXX366 and $0.4 \mu \mathrm{M}$ for the other dinucleotide markers. One primer from each pair was fluorescently labeled with 6-FAM, TET or HEX. Thermocycling profiles were $3 \mathrm{~min}$ at $94{ }^{\circ} \mathrm{C}$ followed by 25 cycles of $94{ }^{\circ} \mathrm{C}(30 \mathrm{~s}), 58{ }^{\circ} \mathrm{C}$ for multiplex-1 and $55^{\circ} \mathrm{C}$ for multiplex-2 (30 s) and $72{ }^{\circ} \mathrm{C}(30 \mathrm{~s})$, followed by a final extension of 15 min at $72{ }^{\circ} \mathrm{C}$ in an MJ Research Hot-Bonnet. Labeled PCR products were analyzed by capillary electrophoresis in an ABI 3100 Genetic Analyzer (Applied Biosystems) and automatically sized relative to an internal standard (PRISM GENESCAN-350 ${ }^{\mathrm{TM}}$ TAMRA, Applied Biosystems) with the GeneScan ${ }^{\mathrm{TM}}$ Analysis 3.5 software (Applied Biosystems).

\section{Mitochondrial DNA}

Mitochondrial DNA (mtDNA) was analyzed in eight wolves of the EEP population (representative of the eight lineages analyzed in this study) by the amplification of a $313 \mathrm{bp}$ fragment of the left domain of the mitochondrial control region (Saccone et al. 1987; Taberlet 1996). Primers used were LoboMit-F 5'-CTCCACCATCAGCACCCAAAG-3' and LoboMit-R 5'-GTAACCCCCACGTTAGTATG-3'. PCR was carried out with the PCR Core Kit Plus (Roche) in $50 \mu$ l of final reaction mixture containing PCR buffer including $2.5 \mathrm{mM}$ of $\mathrm{MgCl}_{2}, 0.2 \mathrm{mM}$ of each dNTP, 0.2 $\mu \mathrm{M}$ of each primer, $0.5 \mathrm{U}$ of Uracil DNA glycosylase and $2 \mathrm{U}$ of Taq polymerase. Thermocycling profiles were $3 \mathrm{~min}$ at $94{ }^{\circ} \mathrm{C}$ followed by 35 cycles of $94{ }^{\circ} \mathrm{C}(30 \mathrm{~s}), 60^{\circ} \mathrm{C}(30 \mathrm{~s})$ and $72{ }^{\circ} \mathrm{C}$ $(30 \mathrm{~s})$, followed by a final extension of $3 \mathrm{~min}$ at $72{ }^{\circ} \mathrm{C}$ in an MJ Research Hot-Bonnet thermocycler. PCR products were purified with the Concert $^{\text {TM }}$ Rapid PCR Purification System (GIBCO BRL) and sequenced using the dideoxy method with Big Dye ${ }^{\mathrm{TM}}$ Terminator Cycle Sequencing Ready Reaction Kit, version 2.0 (Applied Biosystem) and analyzed by capillary electrophoresis in an automated DNA sequencer ABI PRISM 310 (Applied Biosystem). Mitochondrial DNA sequences were aligned using Multalin software (Corpet 1988). 


\section{Data analysis}

Expected $(H)$ and observed $\left(H_{\mathrm{o}}\right)$ heterozygosity within each population were calculated for each of the 13 microsatellites analyzed in this study using the BIOSYS-2 software package (Swofford and Selander 1999). Deviations from Hardy-Weinberg equilibrium were tested using the GENEPOP 3.1 program (Raymond and Rousset 1995) with a Markov chain method to estimate the exact $P$ value (Guo and Thompson 1992). Mean observed and expected heterozygosities, and mean number of alleles $(A)$ were compared between populations by a two-way analysis of variance (Sokal and Rohlf 1995) to take into account the variation between loci. Multilocus observed and expected heterozygosities were compared within each population by a $t$-test for paired comparisons (Sokal and Rohlf 1995). Genetic differentiation between the WILD, EEP and CAPTIVE populations was analyzed by the decomposition of gene diversity (Nei 1973). The FSTAT program (Goudet 2000) was used to estimate the gene diversity for the whole population $\left(H_{\mathrm{T}}\right)$, the mean gene diversity within populations $\left(H_{\mathrm{s}}\right)$, the gene diversity among populations $\left(D_{\mathrm{ST}}\right)$ and the coefficient of gene differentiation $\left(G_{\mathrm{ST}}=D_{\mathrm{ST}} / H_{\mathrm{T}}\right)$. The same software was used to estimate $F_{\mathrm{ST}}$ statistics using the approximation described by Weir and Cockerham (1984). Parentage Exclusion (PE) and Combined Parentage Exclusion (CPE) probabilities were calculated on the basis of the estimated allele frequencies (Jamielson 1994). Polymorphism Information Content (PIC) and PE values were calculated assuming that the genotypes of both parents were known (Botstein et al. 1980; Jamielson 1994).

Genetic pairwise distances among the 74 Iberian wolves and 135 domestic dogs were calculated using the measure $(1-\mathrm{Ps})$ where Ps is the proportion of shared alleles averaged over loci (Bowcock et al. 1994). A tree was constructed from the distance matrix using the Neighbor-Joining clustering algorithm (Saitou and Nei 1987). The distance matrix was obtained with the program MICROSAT (Minch et al. 1995) and the tree derived using the MEGA 2.0 package (Kumar et al. 2001). In addition, all genotypes were screened using a Bayesian admixture procedure implemented in the STRUCTURE software (Pritchard et al. 2000; http://www.pritch.bsd.uchicago.edu). STRUCTURE was used with $10^{6}$ iterations, following a burn-in period of 10,000 iterations, to estimate the number of clusters $(K)$ using only genetic information. The number of clusters was estimated by computing the posterior probabilities for values from $K=1$ to $K=10$. We first analyzed only the wolf samples (WILD, EEP and CAPTIVE). In a second set of runs, both wolves and dogs were included in the analyses. For the wolf samples, this probability appeared to be bimodal (or multimodal) with relatively small changes of $1 n$ $\operatorname{Pr}(X / K)$ beyond $K=1$. When wolf samples were analyzed together with dogs, $\ln \operatorname{Pr}(X / K)$ increased substantially from $K=1$ to $K=2$ with modest increases beyond the latter $K$ value (the maximum was not reached even with $K=10$ ).

The effective number of founders of the EEP population was estimated by two different methods. In both cases, the OVERALL wolf sample was considered as the best representation of the source population. First, we solved for $N$ the equation for the expected number of alleles $(k)$ remaining after a founding event:

$$
k=m-\sum\left(1-p_{i}\right)^{2 N}
$$

where $m$ is the number of alleles and $p_{i}$ the frequency of each allele in the source population (Denniston 1978). Second, we used the following maximum likelihood method. If the frequency of allele $i$ in the source population is $p_{i}$, the probability that this allele is excluded from a founding sample of $2 N$ genes is $\left(1-p_{i}\right)^{2 N}$ and the probability that it is present in such a sample is $1-\left(1-p_{i}\right)^{2 N}$. Therefore, the probability that a particular combination of $k$ alleles is observed in the founding sample (whereas the other $m-k$ alleles are absent) is:

$$
L=\prod_{i=1}^{k}\left[1-\left(1-p_{i}\right)^{2 N}\right] \prod_{j=1}^{m-k}\left(1-p_{j}\right)^{2 N}
$$

The number of founders can be estimated as the $N$ value that maximizes the likelihood function $L$. We found this estimate graphically by plotting the $\ln L$ function and looking for the maximum.

\section{Results}

We sequenced the mitochondrial DNA control region of eight wolves of the EEP population, one wolf from each lineage. We found three (lu1, lu2 
and lu4) of the four haplotypes previously described by Vilà et al. (1999) in the Iberian wolf. A fourth haplotype described for the wild population (lu3) was not represented in any individual of the EEP population. This haplotype, however, had been previously observed in a single individual collected in Portugal (Vilà et al. 1999). The presence of these haplotypes in EPP confirms its origin from Iberian wolves, without apparent introgression of wolves from other localities. Although the mtDNA is maternally inherited and only offers partial information, the relative uniformity of all the sampled wolves, without individuals clearly differentiated from the rest of the population (see below), points in the same direction.

We analyzed the variation at 13 microsatellite loci in 74 Iberian wolves divided in three samples: WILD, EEP and CAPTIVE. All microsatellites were highly polymorphic in the three populations (Table 1; see Appendix A for allelic frequencies per locus and population). Allelic diversity ( $A$, the number of alleles per locus) ranged from two to seven with an average of 4.77 in WILD wolves, from three to eight with an average of 4.92 in the EEP sample and from two to eight with an average of 4.61 in CAPTIVE. No significant differences were observed between the three samples (ANOVA's $F=0.28, \mathrm{df}=2 / 24 ; P=0.76)$. Overall, allelic diversity ranged in the Iberian wolf from 3 to 10 with an average of 6.23 .

Expected $(H)$ and observed $\left(H_{\mathrm{o}}\right)$ heterozygosities were calculated for each microsatellite locus in each of the three samples and in the overall population (see Appendix A). In WILD wolves, $\mathrm{H}$ varied between 0.44 and 0.76 with an average of 0.653 (Table 1). Similar values were observed in the EEP and CAPTIVE samples which show an average $H$ of 0.591 and 0.657 , respectively (the three values are not significantly different:
ANOVA's $F=2.84, \mathrm{df}=2 / 24, P=0.078$ ). Expected heterozygosity in the overall sample was 0.651 . Observed heterozygosity was similarly high in the three samples (Table 1) which are not significantly different (ANOVA's $F=1.66, \mathrm{df}=2 / 24, P=0.21$ ).

Deviations from Hardy-Weinberg $(\mathrm{H}-\mathrm{W})$ were tested for all loci in each population (see Appendix A). In WILD animals, three loci showed a significant deviation from $\mathrm{H}-\mathrm{W}$. In the EEP and CAPTIVE samples, nine and eight loci, respectively, deviated from $\mathrm{H}-\mathrm{W}$ (see Appendix A). All significant deviations (but one) are due to a deficit of heterozygotes and a corresponding excess of homozygotes. The multilocus observed heterozygosity was significantly different from the expected heterozygosity in the EEP sample $(t=-4.59$, $\mathrm{df}=12 ; P=0.0006)$ and the CAPTIVE sample $(t=-5.02 ; \quad \mathrm{df}=12 ; \quad P=0.0003)$ but not in the WILD sample $(t=-2.14 ; \mathrm{df}=12 ; P=0.053)$. The apparent level of consanguinity $F=\left(H-H_{\mathrm{o}}\right) / H$ is generally positive (Table 1 , see also Appendix A). Average $F$ in the WILD, EEP and CAPTIVE samples was $0.153,0.270$ and 0.326 , respectively. The heterozygote deficiency is likely the result of the fragmentation in the populations (Wahlund effect). In fact, the differences are largest for the CAPTIVE and EEP populations, where the entire population is fragmented among different institutions. This fragmentation is associated with a small census and high inbreeding within each institution (see Figure 2). For certain loci (e.g. CXX403), allelic dropout (failure to amplify one of an individual's two alleles) might have contributed to the heterozygote deficit because the DNA samples of the WILD and CAPTIVE populations were old (Pemberton et al. 1995).

Allelic diversity $(A)$ and expected heterozygosity $(H)$ in domestic dogs were 10.38 and 0.79 , respectively (Table 1$)$. Genotype frequencies at all

Table 1. Microsatellite variability estimates in three samples of Iberian wolf and a dog sample

\begin{tabular}{lccccccc}
\hline Sample & $N$ & $A$ & $H_{\mathrm{o}}$ & $H$ & $F$ & PIC & CPE \\
\hline WILD & 17.1 & 4.77 & 0.534 & 0.653 & 0.153 & 0.582 & 0.999 \\
EEP & 28.1 & 4.92 & 0.429 & 0.591 & 0.270 & 0.523 & 0.997 \\
CAPTIVE & 20.9 & 4.61 & 0.460 & 0.657 & 0.326 & 0.587 & 0.999 \\
OVERALL & 66.1 & 6.23 & 0.469 & 0.651 & 0.279 & 0.593 & 0.999 \\
DOG & 126.5 & 10.38 & 0.579 & 0.792 & 0.280 & 0.763 & 0.999 \\
\hline
\end{tabular}

$N=$ sample size (mean number of individuals per locus); $A=$ allelic diversity (mean number of alleles per locus); $H_{o}$ and $H=$ observed and expected heterozygosities; $F=$ inbreeding coefficient, PIC= polymorphism information content; $\mathrm{CPE}=$ combined parentage exclusion. 
13 microsatellite loci deviated significantly from Hardy-Weinberg expectations. Observed heterozygosity $\left(H_{\mathrm{o}}\right)$ was significantly lower than expected heterozygosity $(t=-7.58 ; \quad \mathrm{df}=12 ; \quad P=0.000006)$ resulting in an apparent inbreeding coefficient of $F=0.28$. This value is consistent with the inclusion in the study of dogs from different breeds, which represent reproductively isolated units and produce a Wahlund effect.

The high allelic diversity and high heterozygosity for most loci result in a high polymorphism information content (PIC). For the Iberian wolf, the most informative marker was generally the CXX2001 locus whereas the locus CXX2010 showed the lowest PIC values (see Appendix A). The average PIC value was 0.582 for the WILD sample, 0.523 for the EEP sample, 0.587 for the CAPTIVE sample and 0.593 for the OVERALL sample (Table 1). The combined paternity exclusion (CPE) values were also very high. These observations indicate that this microsatellite set can be used with high confidence for individual identification and to ascertain the paternity in the EEP or other Iberian wolf samples. For the dog sample, the most informative locus was CXX2158 $(\mathrm{PIC}=0.972)$ and that with the lowest PIC $(0.593)$ was CPH5. The average PIC was 0.763 (Table 1).

To evaluate the genetic differentiation between the three Iberian wolf samples, we used Nei's decomposition of gene diversity (Table 2 ). Values of the coefficient of gene differentiation $\left(G_{\mathrm{ST}}\right)$ were generally low (from 0.001 to 0.073 ) with an average value of 0.024 . Thus $97.6 \%$ of total gene diversity was contributed by the diversity found within the samples and only $2.4 \%$ was due to between sample diversity. Therefore, the degree of differentiation was quite small. The multilocus $F_{\mathrm{ST}}$ (Weir and Cockerham 1984) was 0.038 , which although significant $(P<0.01)$ was relatively small indicating again little differentiation between wolf samples. Pairwise $F_{\mathrm{ST}}$ values were 0.0598 for EEP versus WILD, 0.0346 for EEP versus CAPTIVE, and 0.0123 for WILD versus CAPTIVE.

The neighbor-joining tree based on the proportion of shared alleles between individuals showed two clearly separated groups corresponding to Iberian wolves and dogs (Figure 3). The three samples of wolves did not form separate clusters but were interspersed, in good agreement with the little differentiation between them. Cluster analyses were performed using the STRUCTURE software (Pritchard et al. 2000) with the wolf samples alone and with wolves and dogs together. For the wolf samples, the number of clusters varied but each predefined sample (WILD, EEP, CAPTIVE) was not assigned to any single cluster but was split into two or more clusters. This indicates that the three wolf populations can not be easily separated from each other. When wolf samples were analyzed together with dogs and two clusters assumed the three predefined wolf samples were assigned to the same cluster with proportion of membership $\geq 0.985$. Increasing the number of clusters caused the splitting of the dog sample while all wolves remained in one group. We concluded that no consistent differentiation is revealed by this clustering procedure between the three Iberian wolf samples analyzed here.

To estimate the effective number of founders in the EEP population, we considered the OVERALL sample as the best representation of the source wild population. The number of alleles present in the OVERALL sample was 81 whereas 64 alleles were observed in the EEP sample. Thus, 17 alleles have been seemingly lost because of the founder effect. When we solved for $N$ the equation which predicts the number of alleles remaining after a founding event (see above) we get an estimate for the number of founders of 17.8. The alternative method, based in a maximum likelihood approach, gave a similar value, 16.4.

Table 2. Microsatellite genetic differentiation among the WILD, EEP and CAPTIVE samples of Iberian wolf

\begin{tabular}{lllll}
\hline Microsatellite locus & $\mathrm{H}_{\mathrm{T}}$ & $\mathrm{H}_{\mathrm{S}}$ & $\mathrm{D}_{\mathrm{ST}}$ & $\mathrm{G}_{\mathrm{ST}}$ \\
\hline CXX2001 & 0.787 & 0.759 & 0.028 & 0.035 \\
CXX2010 & 0.505 & 0.500 & 0.005 & 0.010 \\
CXX2054 & 0.616 & 0.615 & 0.001 & 0.001 \\
CXX403 & 0.635 & 0.607 & 0.028 & 0.044 \\
CXX410 & 0.747 & 0.692 & 0.055 & 0.073 \\
CXX442 & 0.487 & 0.484 & 0.003 & 0.006 \\
CPH5 & 0.724 & 0.716 & 0.008 & 0.011 \\
CXX366 & 0.476 & 0.480 & 0.004 & 0.008 \\
CXX2158 & 0.648 & 0.652 & 0.004 & 0.006 \\
CPH9 & 0.768 & 0.758 & 0.010 & 0.013 \\
CXX2130 & 0.697 & 0.666 & 0.031 & 0.044 \\
CXX474 & 0.651 & 0.611 & 0.041 & 0.063 \\
CXX459 & 0.752 & 0.750 & 0.002 & 0.003 \\
Total & 0.653 & 0.638 & 0.016 & 0.024 \\
\hline
\end{tabular}

$H_{\mathrm{T}}=$ total gene diversity; $H_{\mathrm{S}}=$ average gene diversity within populations; $\quad D_{\mathrm{ST}}=$ gene diversity among populations; $G_{\mathrm{ST}}=$ coefficient of gene differentiation . 


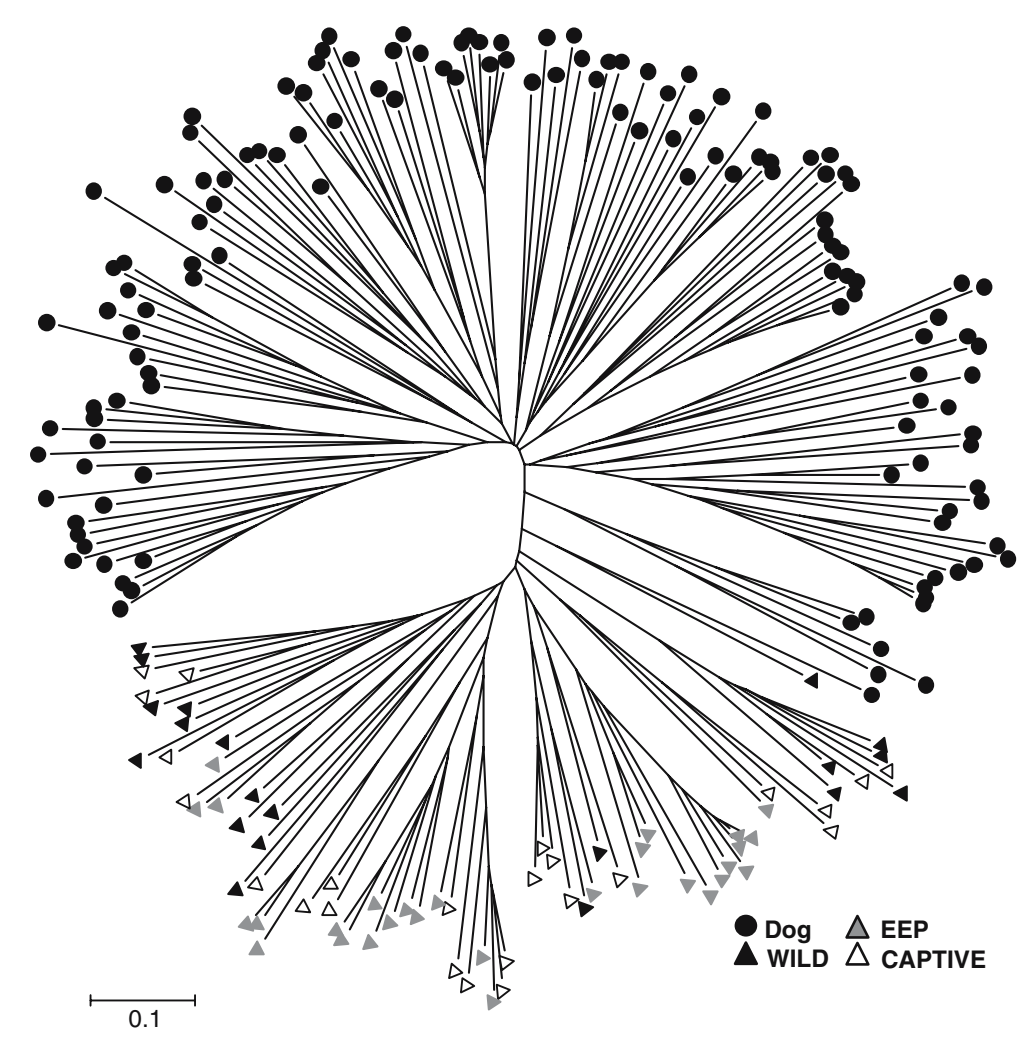

Figure 3. Unrooted neighbor-joining tree of the individual microsatellite multilocus genotypes based on the distance (1-Ps) where Ps is the proportion of shared alleles. Three samples of Iberian wolves (WILD, solid triangles; EEP, gray triangles; CAPTIVE, open triangles) and a sample of dogs (solid circles) belonging to 35 different breeds were included in the analysis.

\section{Discussion}

Genetic variability in Iberian wolves and other canids

Microsatellites have been used to estimate the level of genetic variability in populations of several Canis species (Table 3). In wild populations of gray wolf $(C$. lupus), allelic diversity $(A)$ and expected heterozygosity $(H)$ are usually high reaching the highest values (6.4-6.8 and 0.72-0.74) in North America (particularly Canada), the Balkan Peninsula (Greece and Bulgary) and Latvia and Finland (Table 3). Genetic variability is also relatively high in wild populations of coyote $(C$. latrans). On the other hand, the captive Mexican wolf (C. lupus baileyi) population shows reduced levels of microsatellite variability and the Ethiopian wolf $(C$. simensis), the most endangered canid, shows the lowest variability values of all studied Canis populations. Seemingly, Canis populations show an inverse correlation between microsatellite variability and degree of endangerment, as has been found in other threatened taxa (Spielman et al. 2004).

Our estimates of allele diversity, $A$, and expected heterozygosity, $H$, for the WILD sample of Iberian wolves are relatively high, 4.76 and 0.653 , and comparable in magnitude to those of other wild populations of gray wolf (Table 1). Until now, only one study provided information on the genetic diversity of Iberian wolves using microsatellite markers (Lucchini et al. 2004). In their study, a mixed sample of 32 wild and captive individuals was genotyped for 18 microsatellite loci. Their estimates for $A$ and $H$ (4.7 and 0.60) are similar to those observed here. Both studies indicate relatively high levels of genetic variability in the Iberian wolf populations, comparable to that in the large and continuous North American wolf populations. This suggests that the population changes suffered by the Iberian Wolf in the 20th century (see Introduction, Figure 1) may have not caused a severe reduction of genetic variability. It 
is worth noting however, that all the individuals sampled here and in the previous study come from the relatively large population north of the Duero River. The Iberian wolf populations south of the Duero River are smaller and the situation there is considered critical. The level of genetic variability in these populations is unknown.

\section{Variability levels in the EEP population}

The long term goal of ex situ conservation programs is to preserve enough genetic diversity as to make viable a future reintroduction in natural habitats. The EEP population of Iberian wolves started in 1994 with wolves derived (without genetic management) from 15 founders. It has been managed since then using a minimum kinship strategy (Ballou and Lacy 1995) but within the limitations set by difficulties of individual exchange between institutions (Figure 2). If 15 were the actual number of independent founders, we could assume that a high proportion of the variability present in the wild population would be still found in the EEP population. Several of the

Table 3. Microsatellite variability in populations of gray wolf and other wolf-like canid species

\begin{tabular}{|c|c|c|c|c|c|c|c|}
\hline Taxon & Population & $n$ & $N$ & $A$ & $H_{\mathrm{o}}$ & $H$ & References \\
\hline \multirow[t]{18}{*}{ Canis lupus } & Vancouver & 10 & 12.6 & 3.4 & 0.421 & 0.566 & 1 \\
\hline & Kenai & 10 & 18.9 & 4.1 & 0.536 & 0.581 & 1 \\
\hline & Alberta & 10 & 18.2 & 4.5 & 0.605 & 0.668 & 1 \\
\hline & Minnesota & 10 & 19.8 & 6.3 & 0.532 & 0.686 & 1 \\
\hline & Southern Quebec & 10 & 20.0 & 6.4 & 0.593 & 0.741 & 1 \\
\hline & Northern Quebec & 10 & 13.3 & 4.1 & 0.533 & 0.565 & 1 \\
\hline & Northwest Territories & 10 & 20.9 & 6.4 & 0.547 & 0.721 & 1 \\
\hline & Scandinavian (Captive) & 29 & 29.0 & 2.9 & & 0.51 & 2 \\
\hline & Scandinavian (Wild) & 29 & 13.0 & 3.1 & & 0.52 & 2 \\
\hline & Alberta & 10 & 32.0 & 4.4 & 0.553 & 0.581 & 3 \\
\hline & Central Rocky Mountains & 10 & 59.0 & 4.1 & 0.634 & 0.607 & 3 \\
\hline & Italy & 18 & 103 & 4.4 & 0.440 & 0.490 & 4 \\
\hline & Croatia & 18 & 24.0 & 5.4 & 0.630 & 0.690 & 4 \\
\hline & Greece + Bulgaria & 18 & 39.0 & 6.8 & 0.690 & 0.730 & 4 \\
\hline & Turkey + Israel & 18 & 7.0 & 3.7 & 0.660 & 0.670 & 4 \\
\hline & Saudi Arabia & 18 & 7.0 & 2.4 & 0.480 & 0.420 & 4 \\
\hline & Latvia & 18 & 38.0 & 6.8 & 0.710 & 0.730 & 4 \\
\hline & Finland & 18 & 13.0 & 5.5 & 0.690 & 0.730 & 4 \\
\hline Canis lupus signatus & Spain & 18 & 32.0 & 4.7 & 0.500 & 0.600 & 4 \\
\hline \multirow[t]{3}{*}{ Canis lupus baileyi } & Certificada (Captive) & $10 / 20$ & $20.9 / 20.9$ & $2.5 / 2.5$ & $0.503 / 0.403$ & $0.437 / 0.457$ & $5 / 6$ \\
\hline & Ghost Ranch (Captive) & $10 / 20$ & $10.0 / 10.0$ & $1.3 / 1.5$ & $0.04 / 0.174$ & $0.103 / 0.128$ & $5 / 6$ \\
\hline & Aragon (Captive) & $10 / 20$ & $8.0 / 8.0$ & $1.6 / 1.5$ & $0.3 / 0.211$ & $0.253 / 0.255$ & $5 / 6$ \\
\hline Canis rufus & Captive & 10 & 29.9 & 5.3 & 0.507 & 0.548 & 1 \\
\hline \multirow[t]{2}{*}{ Canis simensis } & Web Valley & 9 & 22.8 & 2.8 & 0.304 & 0.355 & 7 \\
\hline & Sanetti & 9 & 16.4 & 2 & 0.179 & 0.201 & 7 \\
\hline \multirow[t]{6}{*}{ Canis latrans } & Washington & 10 & 15.9 & 5.8 & 0.54 & 0.666 & 1 \\
\hline & Kenai & 10 & 12.8 & 4.9 & 0.554 & 0.627 & 1 \\
\hline & Alberta & 10 & 16.8 & 6.1 & 0.653 & 0.702 & 1 \\
\hline & Minnesota & 10 & 18.4 & 5.7 & 0.649 & 0.709 & 1 \\
\hline & Maine & 10 & 16.2 & 6.1 & 0.596 & 0.702 & 1 \\
\hline & California & 10 & 22.1 & 6.9 & 0.502 & 0.644 & 1 \\
\hline \multirow[t]{2}{*}{ Canis familiaris } & 32 breeds & 9 & 35.0 & 6.4 & 0.729 & 0.57 & 7 \\
\hline & 24 breeds & 10 & 95.0 & 7 & 0.55 & 0.75 & 8 \\
\hline
\end{tabular}

$n=$ number of microsatellite loci; $N=$ sample size (mean number of individuals per locus); $A=$ allelic diversity (mean number of alleles per locus); $H_{\mathrm{o}}$ and $H$ : observed and expected heterozygosities. References: (1) Roy et al. (1994); (2) Ellegren (1999); (3) Forbes and Boyd (1996); (4) Lucchini et al. (2004); (5) Garcia-Moreno et al. (1996) (6) Hedrick et al. (1997); (7) Gottelli et al. (1994); (8) Altet et al. (2001). 
founding individuals, however, were of unknown origin. Thus the effective number of founders was doubtful and the actual level of genetic variability in the EEP population unknown.

Our estimates of allelic diversity $(A)$ and expected heterozygosity $(H)$ in the EEP population, 4.92 and 0.591 , are comparable to those of the WILD sample (Table 1). This indicates that a substantial proportion of the variability present in the wild is preserved in the EEP population. As a matter of fact, the two variability measures were not significantly different when the three samples included in this study (WILD, EEP and CAPTIVE) were compared. Thus, the pooled sample (OVERALL) likely provides the best estimate of variability levels in the Iberian wolf population. The absence of a significant differentiation between the WILD, EEP and CAPTIVE samples is corroborated by the decomposition of the gene diversity. The proportion of the total gene diversity which is contributed by differences between the three samples is only $2.4 \%$. Thus each of the three samples contains almost all $(97.6 \%)$ of the total diversity. The absence of differentiation between the three Iberian wolf samples and the representation of wild genetic diversity in the EEP population are also evident when considering the neighbor-joining tree (Figure 3). In this tree, as in the Bayesian clustering analysis, members of the three samples appear interspersed without a clearcut clustering of any groups.

The number of founders in the EEP population was estimated by two different methods. The first method, based on the number of alleles present in the EEP population, gave an estimate of 17.8. The second method, based on a maximum likelihood approach, takes into account not only the number of alleles but also which particular set of alleles is present in the EEP population. This method resulted in a value, 16.4, very close to the number of founders in the studbook. These results suggest that all the founders were in fact genetically independent and all of them contributed effectively to the genetic make-up of the EEP population. The relatively high number of independent founders and the subsequent genetic management explains the high proportion of the original variability still present in the EEP population. The EEP population has a much higher genetic diversity than the captive Scandinavian wolf population (Ellegren 1999), the three captive Mexican wolf populations
(García-Moreno et al. 1996; Hedrick et al. 1997) or the captive C. rufus population (Roy et al. 1994). These captive populations were started with a smaller number of founders than the EEP population. In fact, a significant correlation between expected heterozygosity and number of founders is observed when all six populations are analyzed together $(r=0.89, \mathrm{df}=5 ; P=0.019)$. This correlation explains $\sim 80 \%$ of the variance in heterozygosity and suggests that the number of founders is the chief determinant of the extant genetic diversity in these captive breeding populations. The captive Scandinavian and Mexican wolf populations show signs of different degrees of inbreeding depression (Laikre and Ryman 1991; Laikre et al. 1993; Fredrickson and Hedrick 2002; however, see also Kalinowski et al. 1999). Nevertheless, the captive Mexican wolf population is used for reintroduction in the South West of the United States (USFWS 1998). So far, no signs of inbreeding depression have been observed in captive Iberian wolves, although no systematic study has been conducted. However, the observed heterozygosity is significantly lower than expected under HardyWeinberg equilibrium for the EEP sample. This is the result of the fragmentation induced by the fact that there are multiple captive breeding facilities, which has led to high levels of inbreeding in most lineages (Figure 2). This high inbreeding could lead to fitness depression in the future as observed in other captive wolf breeding programs. A management aimed at minimizing kinship (Ballou and Lacy 1995) is in place, but its success will be dependent on facilitating the exchange of individuals between centers.

\section{Microsatellite variation in Iberian wolf and domestic dogs}

Hybridization can occur between many species of the canid family (Gray 1954; Lehman et al. 1991; Mercure et al. 1993; Roy et al. 1996; Wayne and Brown 2001). Wolves and dogs coexist across most of the wolf's range, and their close relationship, caused by their recent divergence (Vilà et al. 1997), suggests that hybridization could be a problem for the conservation of wolf populations (Nowak 1979; Wayne and Jenks 1991; Gottelli et al. 1994; Roy et al. 1994). Hybridization has the potential to produce morphological, physiological and behavioral changes in domestic and wild canids 
(Mengel 1971; Thurber and Peterson 1991; Lariviere and Crete 1993). For example, wolf-dog hybrids tend to have synanthropic behavior and are more difficult to control than wolves (Andersone et al. 2002). In the Iberian Peninsula, wolves can be found at low densities in many rural areas, coexisting with agricultural and livestock activities, and occasional wolf-dog hybridization could occur. Genetic analyses did not show any evidence of introgression of dog mitochondrial DNA in Spanish and Italian wolves (Vilà and Wayne 1999; Randi et al. 2000). More recent studies by microsatellite genotyping reported evidence of occasional wolf-dog hybridization in Italy and elsewhere in Europe (Andersone et al. 2002; Randi and Lucchini 2002; Vilà et al. 2003).

In our study, the sample of domestic dogs shows high microsatellite variability (Table 1). The allelic diversity $(A)$ in particular is much higher than for the Iberian wolf (10.5 versus 6.2). Among the 136 alleles observed in domestic dogs, 63 are shared between dogs and Iberian wolves whereas 72 are exclusive of dogs. On the other hand, out of the 80 alleles observed in the Iberian wolf, only 17 alleles are exclusive of wolves. The differentiation between dogs and Iberian wolves is clearly demonstrated in the phylogenetic tree built with all individuals analyzed here (Figure 3 ). This tree shows two neatly separated groups with a single individual overlap and the cluster analysis with the program STRUCTURE showed that wolves and dogs are clearly separated. These results suggest that no individual wolf of hybrid origin has been included in our Iberian wolf sample and emphasize the genetic divergence between wolves and domestic dogs. They also indicate that our set of 13 microsatellite loci provide a powerful diagnostic test to distinguish wolves, dogs and their hybrids.

\section{Acknowledgements}

This study would not have been possible without the help of the institutions who collected and provided wolf and dog samples: Zoo Aquarium de la casa de Campo, Parc Zoològic de Barcelona, Parque Ecológico Bizcaia, Jardim Zoológico de Lisboa, Parque Zoológico de Jerez, Zoológico Municipal de Guadalajara, Zoológico de Santillana del Mar, Safari Park Vergel, and Servei Veterinari de Genètica Molecular (UAB). This work was supported by grant BMC2002-01708 from the Dirección General de Investigación, Ministerio de Ciencia y Tecnología (Spain).

\section{Appendix A}

Table A.1. Allele frequencies, expected and observed heterozygosities $\left(H\right.$ and $\left.H_{\mathrm{o}}\right)$, inbreeding coefficient $(F)$, polymorphism information content (PIC) and parentage exclusion (PE) for 13 microsatellite loci analyzed in three samples of Iberian wolf and a dog sample. $N=$ sample size (number of individuals analyzed per locus)

\begin{tabular}{|c|c|c|c|c|c|c|}
\hline LOCUS & ALLELES & WILD & EEP & CAPTIVE & OVERALL & DOG \\
\hline \multirow[t]{16}{*}{ CXX2001 } & 120 & & & & & 0.004 \\
\hline & 124 & & & & & 0.026 \\
\hline & 128 & & & & & 0.163 \\
\hline & 132 & 0.053 & 0.328 & 0.071 & 0.174 & 0.096 \\
\hline & 136 & 0.105 & 0.034 & 0.143 & 0.087 & 0.011 \\
\hline & 140 & 0.421 & 0.138 & 0.429 & 0.304 & 0.252 \\
\hline & 144 & 0.237 & 0.345 & 0.190 & 0.268 & 0.285 \\
\hline & 148 & 0.079 & 0.138 & 0.095 & 0.109 & 0.133 \\
\hline & 150 & 0.105 & 0.017 & 0.048 & 0.051 & \\
\hline & 154 & & & & & 0.026 \\
\hline & 156 & & & 0.024 & 0.007 & 0.004 \\
\hline & $\mathbf{N}$ & 19 & 29 & 21 & 69 & 135 \\
\hline & $H_{\mathrm{o}}$ & 0.579 & 0.448 & 0.619 & 0.536 & 0.681 \\
\hline & $H$ & 0.755 & 0.747 & 0.761 & 0.789 & 0.803 \\
\hline & $F$ & 0.238 & $0.404 * * *$ & 0.190 & $0.322 * * *$ & $0.152 * * *$ \\
\hline & PIC & 0.700 & 0.689 & 0.713 & 0.751 & 0.772 \\
\hline
\end{tabular}


Table A.1. Continued

\begin{tabular}{|c|c|c|c|c|c|c|}
\hline LOCUS & ALLELES & WILD & EEP & CAPTIVE & OVERALL & DOG \\
\hline & PE & 0.522 & 0.499 & 0.516 & 0.580 & 0.610 \\
\hline \multirow[t]{13}{*}{ CXX2010 } & 214 & & 0.017 & & 0.007 & \\
\hline & 222 & 0.425 & 0.242 & 0.340 & 0.328 & 0.026 \\
\hline & 226 & 0.575 & 0.741 & 0.660 & 0.665 & 0.159 \\
\hline & 230 & & & & & 0.396 \\
\hline & 234 & & & & & 0.204 \\
\hline & 238 & & & & & 0.196 \\
\hline & 242 & & & & & 0.019 \\
\hline & $\mathbf{N}$ & 20 & 29 & 25 & 73 & 135 \\
\hline & $H_{\mathrm{o}}$ & 0.650 & 0.172 & 0.208 & 0.315 & 0.585 \\
\hline & $H$ & 0.529 & 0.492 & 0.467 & 0.502 & 0.739 \\
\hline & F & -0.307 & $0.572 * *$ & $0.559 * *$ & $0.307 * *$ & $0.209 * * *$ \\
\hline & PIC & 0.369 & 0.327 & 0.348 & 0.355 & 0.696 \\
\hline & PE & 0.185 & 0.171 & 0.174 & 0.181 & 0.508 \\
\hline \multirow[t]{16}{*}{ CXX2054 } & 144 & 0.025 & & & 0.007 & 0.048 \\
\hline & 148 & 0.075 & & 0.196 & 0.070 & 0.026 \\
\hline & 150 & 0.325 & 0.293 & 0.239 & 0.289 & 0.144 \\
\hline & 154 & 0.450 & 0.638 & 0.522 & 0.557 & 0.278 \\
\hline & 158 & 0.050 & & & 0.014 & 0.141 \\
\hline & 162 & 0.050 & 0.069 & & 0.056 & 0.089 \\
\hline & 166 & 0.025 & & 0.043 & 0.007 & 0.137 \\
\hline & 170 & & & & & 0.089 \\
\hline & 174 & & & & & 0.044 \\
\hline & 178 & & & & & 0.004 \\
\hline & $\mathbf{N}$ & 20 & 29 & 23 & 72 & 135 \\
\hline & $H_{\mathrm{o}}$ & 0.700 & 0.448 & 0.182 & 0.437 & 0.741 \\
\hline & $H$ & 0.697 & 0.511 & 0.627 & 0.603 & 0.845 \\
\hline & F & -0.004 & 0.125 & $0.715^{* * *}$ & $0.277 * * *$ & $0.125^{* *}$ \\
\hline & PIC & 0.630 & 0.428 & 0.572 & 0.540 & 0.825 \\
\hline & PE & 0.441 & 0.243 & 0.370 & 0.348 & 0.691 \\
\hline \multirow[t]{22}{*}{ CXX403 } & 232 & & & & & 0.004 \\
\hline & 244 & & & & & 0.004 \\
\hline & 252 & & & & & 0.004 \\
\hline & 258 & & & & & 0.008 \\
\hline & 260 & & & & & 0.028 \\
\hline & 262 & & & & & 0.082 \\
\hline & 264 & 0.400 & 0.768 & 0.420 & 0.549 & 0.152 \\
\hline & 266 & & & & & 0.195 \\
\hline & 268 & 0.150 & 0.036 & 0.200 & 0.118 & 0.066 \\
\hline & 270 & 0.275 & 0.178 & 0.340 & 0.264 & 0.028 \\
\hline & 272 & 0.150 & 0.018 & 0.040 & 0.062 & 0.066 \\
\hline & 274 & 0.025 & & & 0.007 & 0.121 \\
\hline & 276 & & & & & 0.093 \\
\hline & 278 & & & & & 0.090 \\
\hline & 280 & & & & & 0.028 \\
\hline & 282 & & & & & 0.023 \\
\hline & 284 & & & & & 0.008 \\
\hline & $\mathbf{N}$ & 20 & 28 & 24 & 72 & 128 \\
\hline & $H_{\mathrm{o}}$ & 0.100 & 0.357 & 0.250 & 0.250 & 0.703 \\
\hline & $H$ & 0.737 & 0.384 & 0.678 & 0.631 & 0.892 \\
\hline & F & $0.867 * * *$ & 0.071 & $0.636^{* * *}$ & $0.596 * * *$ & $0.212 * * *$ \\
\hline & PIC & 0.672 & 0.337 & 0.601 & 0.556 & 0.879 \\
\hline
\end{tabular}


Table A.1. Continued

\begin{tabular}{|c|c|c|c|c|c|c|}
\hline LOCUS & ALLELES & WILD & EEP & CAPTIVE & OVERALL & DOG \\
\hline \multirow{20}{*}{ CXX410 } & $\mathrm{PE}$ & 0.477 & 0.189 & 0.392 & 0.360 & 0.777 \\
\hline & 86 & & & & & 0.007 \\
\hline & 93 & 0.175 & 0.327 & 0.375 & 0.292 & 0.040 \\
\hline & 97 & & & & & 0.101 \\
\hline & 102 & & & & & 0.015 \\
\hline & 105 & & & & & 0.067 \\
\hline & 108 & 0.450 & 0.052 & 0.188 & 0.208 & 0.118 \\
\hline & 110 & 0.050 & & 0.021 & 0.021 & 0.096 \\
\hline & 112 & 0.100 & 0.500 & 0.354 & 0.347 & 0.193 \\
\hline & 114 & 0.225 & 0.121 & 0.062 & 0.132 & 0.037 \\
\hline & 116 & & & & & 0.244 \\
\hline & 118 & & & & & 0.056 \\
\hline & 120 & & & & & 0.004 \\
\hline & 122 & & & & & 0.022 \\
\hline & $\mathbf{N}$ & 20 & 29 & 24 & 73 & 135 \\
\hline & $H_{\mathrm{o}}$ & 0.6 & 0.655 & 0.609 & 0.625 & 0.755 \\
\hline & $H$ & 0.722 & 0.636 & 0.715 & 0.738 & 0.862 \\
\hline & $F$ & 0.172 & -0.030 & 0.152 & $0.154 * *$ & $0.124 * * *$ \\
\hline & PIC & 0.661 & 0.560 & 0.638 & 0.686 & 0.843 \\
\hline & PE & 0.469 & 0.358 & 0.435 & 0.489 & 0.721 \\
\hline \multirow[t]{15}{*}{ CXX442 } & 139 & & & & & 0.004 \\
\hline & 155 & 0.125 & 0.179 & 0.208 & 0.176 & \\
\hline & 157 & 0.225 & 0.053 & 0.167 & 0.134 & 0.088 \\
\hline & 159 & & & & & 0.007 \\
\hline & 161 & 0.650 & 0.768 & 0.625 & 0.690 & 0.098 \\
\hline & 163 & & & & & 0.564 \\
\hline & 165 & & & & & 0.129 \\
\hline & 167 & & & & & 0.087 \\
\hline & 169 & & & & & 0.023 \\
\hline & $\mathbf{N}$ & 20 & 28 & 24 & 72 & 132 \\
\hline & $H_{\mathrm{o}}$ & 0.600 & 0.393 & 0.391 & 0.451 & 0.401 \\
\hline & $H$ & 0.524 & 0.382 & 0.544 & 0.478 & 0.641 \\
\hline & $F$ & -0.149 & -0.028 & $0.285^{*}$ & 0.058 & $0.375^{* * *}$ \\
\hline & $\mathrm{PIC}$ & 0.453 & 0.334 & 0.480 & 0.427 & 0.612 \\
\hline & PE & 0.268 & 0.185 & 0.288 & 0.251 & 0.434 \\
\hline \multirow[t]{14}{*}{ CPH5 } & 105 & & & & & 0.019 \\
\hline & 107 & 0.067 & & 0.022 & 0.023 & 0.288 \\
\hline & 109 & & 0.017 & & 0.015 & 0.115 \\
\hline & 111 & 0.500 & 0.310 & 0.364 & 0.371 & 0.500 \\
\hline & 113 & 0.100 & 0.052 & 0.136 & 0.091 & 0.078 \\
\hline & 119 & 0.067 & 0.017 & & 0.023 & \\
\hline & 121 & 0.266 & 0.345 & 0.364 & 0.333 & \\
\hline & 123 & & 0.259 & 0.114 & 0.144 & \\
\hline & $\mathbf{N}$ & 15 & 29 & 22 & 66 & 134 \\
\hline & $H_{\mathrm{o}}$ & 0.467 & 0.552 & 0.636 & 0.561 & 0.410 \\
\hline & $H$ & 0.683 & 0.727 & 0.724 & 0.726 & 0.650 \\
\hline & $F$ & $0.324 * *$ & $0.245^{*}$ & 0.124 & $0.230 * * *$ & $0.369 * * *$ \\
\hline & PIC & 0.612 & 0.661 & 0.650 & 0.675 & 0.593 \\
\hline & PE & 0.421 & 0.459 & 0.452 & 0.485 & 0.396 \\
\hline \multirow[t]{3}{*}{ CXX366 } & 156 & & 0.050 & & 0.009 & \\
\hline & 160 & 0.067 & 0.025 & 0.150 & 0.091 & 0.345 \\
\hline & 164 & 0.700 & 0.750 & 0.675 & 0.701 & 0.388 \\
\hline
\end{tabular}


Table A.1. Continued

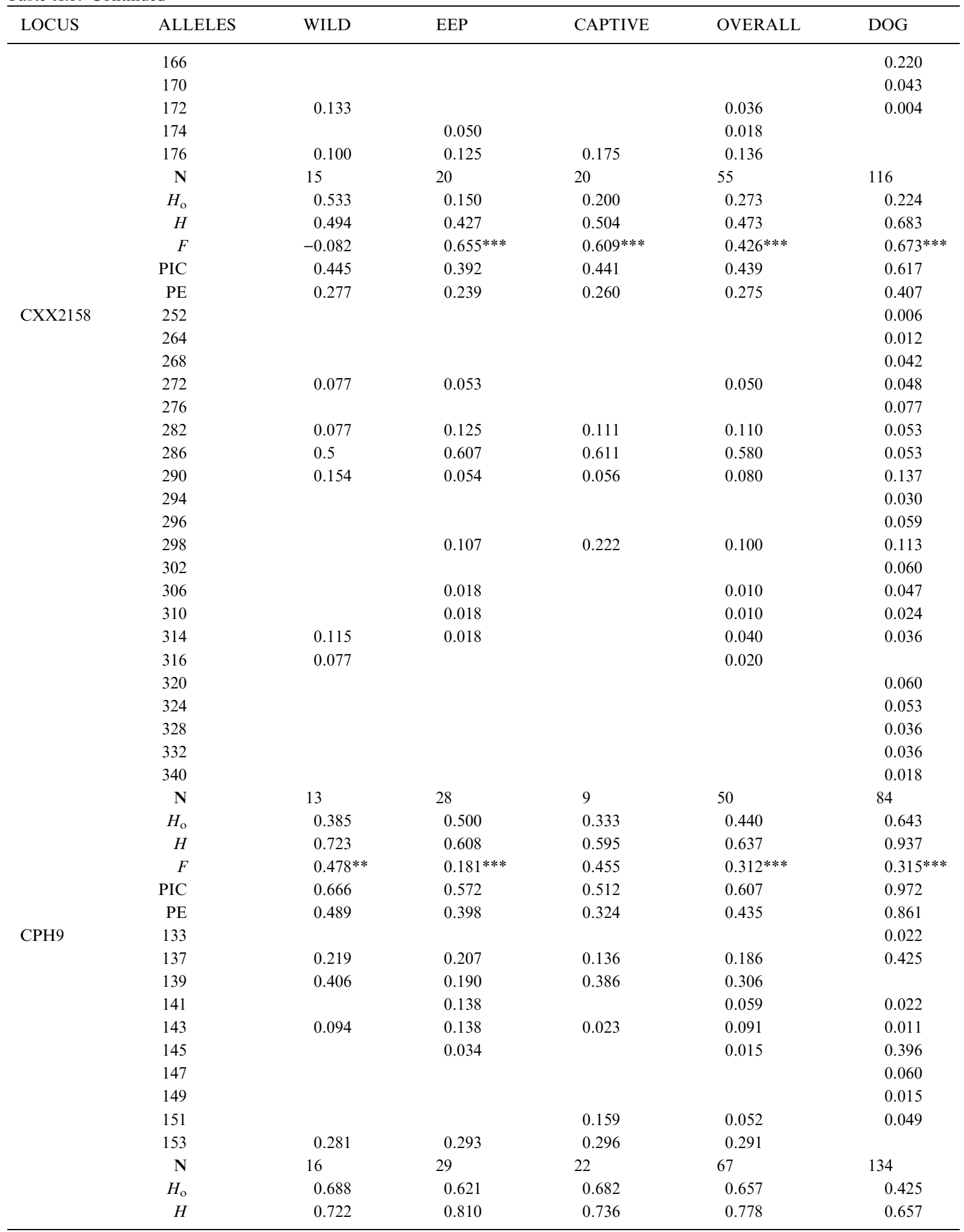


Table A.1. Continued

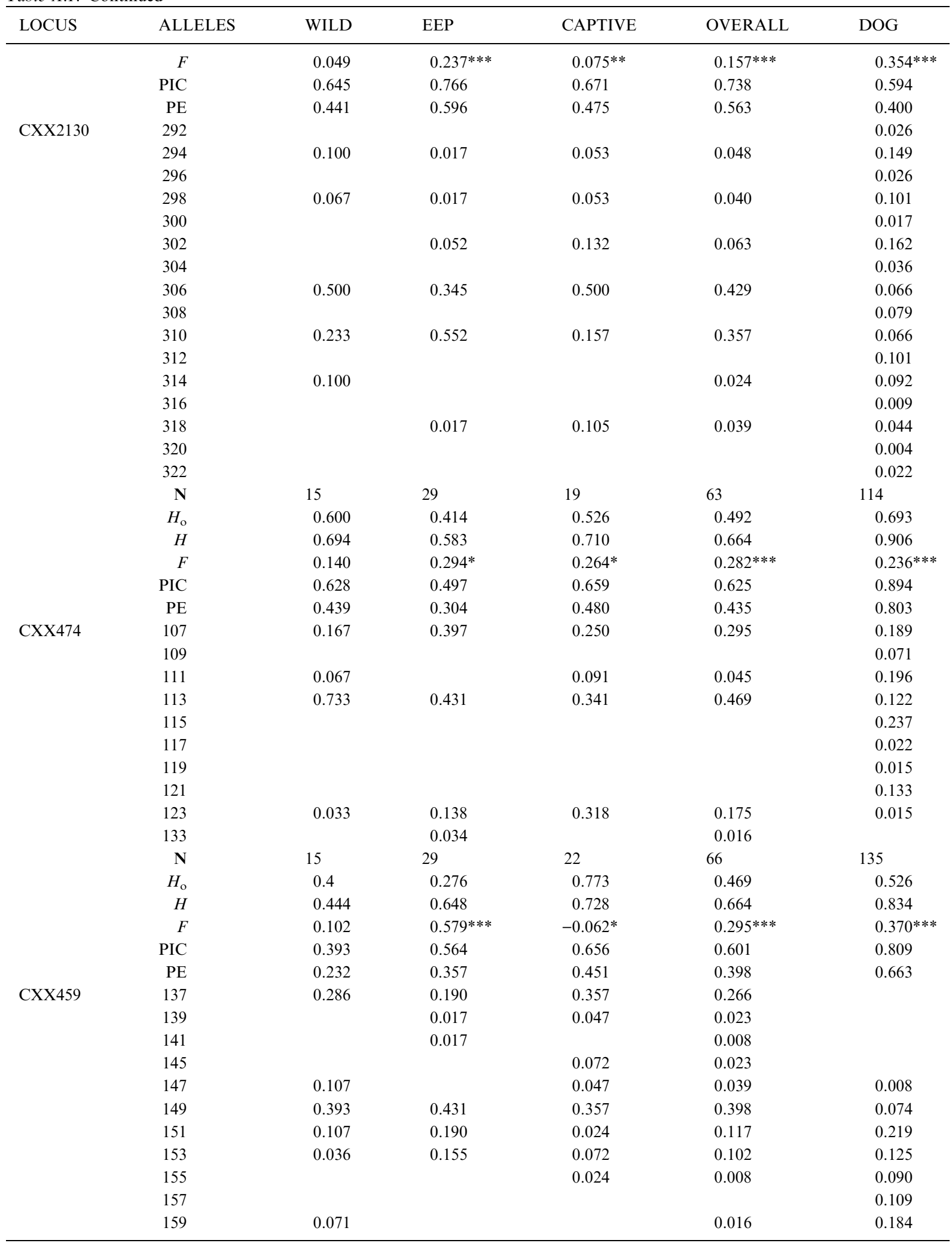


Table A.1. Continued

\begin{tabular}{rcccccc}
\hline LOCUS & ALLELES & WILD & EEP & CAPTIVE & OVERALL & DOG \\
\hline 161 & & & & & 0.191 \\
N & 14 & 29 & 21 & 04 & 128 \\
$H_{\mathrm{o}}$ & 0.643 & 0.586 & 0.571 & 0.594 & 0.734 \\
$H$ & 0.762 & 0.730 & 0.747 & 0.749 & 0.844 \\
$F$ & 0.161 & $0.200^{* *}$ & 0.239 & $0.209^{* *}$ & $0.130^{* * *}$ \\
PIC & 0.695 & 0.675 & 0.688 & 0.708 & 0.820 \\
PE & 0.512 & 0.484 & 0.509 & 0.532 & 0.679 \\
\hline
\end{tabular}

$* P<0.05 ; * * P<0.01 ; * * * P<0.001$.

\section{References}

Alonso P, Barrientos LM, Fernández A, Llaneza L, Rico M, de la Torre JA, Vilà C (1999) Situación actual del lobo en España. Quercus, 157, 24-25.

Altet L, Francino O, Sánchez A (2001) Microsatellite polymorphism in closely related dogs. J. Hered., 92, 276-279.

Andersone Z, Lucchini V, Randi E, Ozolins J (2002) Hybridisation between wolves and dogs in Latvia as documented using mitochondrial and microsatellite DNA markers. Mamm. Biol., 67, 79-90.

Ballou JD, Foose TJ (1996) Demographic and genetic management of captive populations. In: Wild Mammals in Captivity. Principles and Techniques (eds. Kleiman DG, Allen ME, Thompson KV, Lumpkin S), pp. 263-283. The University of Chicago Press, Chicago.

Ballou JD, Lacy RC (1995) Identifying genetically important individuals for management of genetic diversity in pedigreed populations. In: Population Management for Survival and Recovery: Analytical Methods and Strategies in Small Population Conservation (eds. Ballou JD, Gilpin M, Foose TJ), pp. 76-111. Columbia University Press, New York.

Baillie JEM, Hilton-Taylor C, Stuart SN, (eds.) (2004) IUCN Red List of Threatened Species. A Global Species Assessment, IUCN - The World Conservaqtion Union, Gland, Switzerland.

Blanco JC, Cuesta L, Reig S (1992) Distribution, status, and conservation problems of the wolf Canis lupus in Spain. Biol. Conserv., 60, 73-80.

Blanco JC, Cortés Y (2002) Ecología, censos, percepción y evolución del lobo en España: Análisis de un conflicto, Sociedad Española para la Conservación y Estudio de los Mamíferos, Málaga, Spain.

Boitani L (2003) Wolf conservation and recovery In: Wolves. Behavior, Ecology, and Conservation (eds. Mech LD, Boitani L), pp. 317-344. The University of Chicago Press, Chicago.

Botstein D, White RL, Skolnick M, Davis RW (1980) Construction of a genetic linkage map in man using restriction fragment length polymorphisms. Am. J. Hum. Genet., 32, 314-331.

Bouman I, Bouman J (1994) The history of Przewalski's horse. In: Przewalski's Horse: The History and Biology of an Endangered Species (eds. Boyd L, Houpt KA), pp. 5-39. State University of New York Press, Albany, New York.

Bowcock AM, Ruiz-Linares A, Tomfohrde J, Minch E, Kidd JR, Cavalli-Sforza LL (1994) High resolution of human evolutionary trees with polymorphic microsatellite. Nature, 368, 455-457.

Cabrera A (1907) Los lobos de España. Bol. R. Soc. Esp. Hist. Nat., 7, 193-198.

Corpet F (1988) Multiple sequence alignment with hierarchical clustering. Nucleic Acids Res., 16, 10881-10890.

Crandall KA, Bininda-Emonds OR, Mace GM, Wayne RK (2000) Considering evolutionary processes in conservation biology. Trends Ecol. Evol., 15, 290-295.

Denniston C (1978) Small population size and genetic diversity: implications for endangered species In: Endangered Birds: Management Techniques for Preserving Threatened Species (eds. Temple ), pp. 281-289. University of Wisconsin Press, Madison.

Ellegren H (1999) Inbreeding relatedness in Scandinavian grey wolves Canis lupus. Hereditas, 130, 239-244.

Enseñat C (1996) European Regional Studbook. Lobo ibérico Canis lupus signatus, Parc Zoològic de Barcelona, Barcelona, Spain.

Forbes SH, Boyd DK (1996) Genetic variation of naturally colonizing wolves in the central rocky mountains. Conserv. Biol., 10, 1082-1090.

Francino O, Amills M, Sánchez A (1997) Canine Mhc DRB1 phenotyping by PCR-RFLP analysis. Anim. Genet., 28, 41-45.

Francisco LV, Langston AA, Mellersh CS, Neal CL, Ostrander EA (1996) A class of highly polymorphic tetranucleotide repeats for the canine genetic mapping. Mamm. Genome, $\mathbf{7}$, 359-362.

Frankham R, Ballou JD, Briscoe DA (2002) Introduction to Conservation Genetics, Cambridge University Press, Cambridge.

Fredholm M, Wintero AK (1995) Variation of short tandem repeats within and between species belonging to the Canidae family. Mamm. Genome, 6, 11-18.

Fredrickson R, Hedrick P (2002) Body size in endangered Mexican wolves: effects of inbreeding and cross-lineage matings. Anim. Conserv., 5, 39-43.

Garcia-Moreno J, Matocq MD, Roy MS, Geffen E, Wayne RK (1996) Relationships ang genetic purity of the endangered mexican wolf based on análisis of microsatellite loci. Conserv. Biol., 10, 376-389.

Geyer CJ, Ryder OA, Chemnick LG, Thompson EA (1993) Analysis of relatedness in the California condors, from DNA fingerprints. Mol. Biol. Evol., 10, 571-589.

Gottelli D, Sillero-Zubiri C, Applebaum GD, Roy MS, Girman DJ, Garcia-Moreno J, Ostranders EA, Wayne RK (1994) 
Molecular genetics of the most endangered canid: the Ethiopian wolf Canis simensis. Mol. Ecol., 3, 301-312.

Goudet J (2000) FSTAT Version 2.9.1. Computer Package for $P C s$, Institute of Ecology, Biology building, UNIL, CH1015, Lausane, Switzerland.

Gray AP (1954) Mammalian Hybrids. A Check-List with Bibliography, Commonwealth Agricultural Bureaux, Famham Royal, Bucks, UK.

Guo SW, Thompson EA (1992) Performing the exact test of Hardy-Weinberg proportions for multiple alleles. Biometrics, 48, 361-372.

Hedrick PW, Miller PS, Geffen E, Wayne RK (1997) Genetic evaluation of the three captive mexican wolf lineages. Zoo Biol., 16, 47-69.

Hedrick PW (2005) Genetics of Populations, 3rd edn. Jones and Bartlett Publishers, Sudbyry, Massachusetts.

Jamielson A (1994) The effectiveness of using codominant polymorphic allelic series for (1) checking pedigrees and (2) distinguishing full-sib pair members. Anim. Genet., 25, 37-44.

Kalinowski ST, Hedrick PW, Miller PS (1999) No inbreeding depression observed in Mexican and red wolf captive breeding programs. Conserv. Biol., 13, 131-137.

Kumar S, Tamura K, Jakobsen IB, Nei M (2001) MEGA2: molecular evolutionary genetics analysis software. Bioinformatics, 17, 1244-1245.

Laikre L, Ryman N (1991) Inbreeding depression in a captive wolf (Canis lupus) population. Conserv. Biol., 5, 33-40.

Laikre L, Ryman N, Thompson A (1993) Hereditary blindness in a captive wolf (Canis lupus) population: frequency reduction of a deleterious allele in relation to gene conservation. Conserv. Biol., 7, 592-601.

Lariviere S, Crete M (1993) The size of eastern coyotes (Canis latrans): a comment. J. Mammal., 74, 1072-1074.

Lehman N, Eisenhawer A, Hansen K, Mech LD, Peterson RO, Gogan PJP, Wayne RK (1991) Introgression of coyote mitochondrial-DNA into sympatric North-American Gray wolf Populations. Evolution, 45, 104-119.

Lucchini V, Galov A, Randi E (2004) Evidence of genetic distinction and long-term population decline in wolves (Canis lupus) in the Italian Apennines. Mol. Ecol., 13, 523-536.

Mellersh CS, Langston AA, Acland GM, Fleming MA, Ray K, Wiegand NA, Francisco LV, Gibbs M, Aguirre G, Ostrander EA (1997) A linkage map of the canine genome. Genomics, 46, 326-336.

Mellersh CS, Hitte C, Richman M, Vignaux F, Priat C, Jouquand S, Werner P, Andraae C, DeRose S, Patterson DF, Ostrander EA, Galibert F (2000) An integrated linkageradiation hybrid map of the canine genome. Mamm. Genome, 11, 120-130.

Mengel RM (1971) A study of dog-coyotes hybrids and implications concerning hybridization in Canis. J. Mammal., 52, 316-336.

Mercure A, Ralls K, Koepfli KP, Wayne RK (1993) Genetic subdivisions among small canids - mitochondrial-DNA differentiation of swift, kit, and arctic foxes. Evolution, 47, 1313-1328.

Minch E, Ruiz-Linares A, Goldstein DB, Feldman MW, Cavalli-Sforza LL (1995) Microsat (version 1.4d): a computer program for calculating various statistics on microsatellite allele data. http://www.human.stanford.edu/microsat/ microsat.html.
Nei M (1973) Analysis of gene diversity in subdivided populations. Proc. Natl. Acad. Sci. USA, 70, 3321-3323.

Nowak RM (1979) North American Quaternary Canis. No. 6, Museum of Natural History, University of Kansas, Lawrence. Nowak RM (2003) Wolf evolution and taxonomy In: Wolves. Behavior, Ecology, and Conservation (eds. Mech LD, Boitani L), pp. 239-258. The University of Chicago Press, Chicago.

Ostrander EA, Mapa FA, Yee M, Rine J (1995) One hundred and one simple sequence repeats-based markers for the canine genome. Mamm. Genome, 6, 192-195.

Pemberton JM, Slate J, Bamcroft DR, Barrett JA (1995) Nonamplifying alleles at microsatellites loci: a caution for parentage and population studies. Mol. Ecol., 4, 294-352.

Pritchard JK, Stephens M, Donnelly P (2000) Inference of population structure using multilocus genotype data. Genetics, 155, 945-959.

Randi E, Lucchini V, Christensen MF, Mucci N, Funk SM, Dolf G, Loeschcke V (2000) Mitochondrial DNA variability in Italian and East European wolves: detecting the consequences of small population size and hybridization. Conserv. Biol., 14, 464-473.

Randi E, Lucchini V (2002) Detecting rare introgression of domestic dog genes into wild wolf (Canis lupus) populations by Bayesian admixture analyses of microsatellite variation. Conserv. Biol., 3, 31-45.

Raymond M, Rousset F (1995) GENEPOP (Version 3.1): population genetics software for exact test and ecumenicism. J. Hered., 86, 248-249.

Roy MS, Geffen E, Smith D, Ostrander EA, Wayne RK (1994) Patterns of differentiation and hybridization in North American wolflike canids, revealed by analysis of microsatellite loci. Mol. Biol. Evol., 11, 553-570.

Roy MS, Geffen E, Smith D, Wayne RK (1996) Molecular genetics of pre-1940 red wolves. Conserv. Biol., 10, 14131424.

Russello MA, Amato G (2004) Ex situ population management in the absence of pedigree information. Mol. Ecol., 13, 28292840.

Saccone C, Attimonelli M, Sbisa E (1987) Structural elements highly preserved during the evolution of the D-loop-containing region in vertebrate mitochondrial DNA. J. Mol. Evol., 26, 205-211.

Saitou N, Nei M (1987) The neighbor-joining method: a new method for reconstructing phylogenetic trees. Mol. Biol. Evol., 4, 406-425.

Sillero-Zubiri C, Hoffman M, Macdonald DW (2004) Canids: foxes, wolves, jackals and dogs. Status survey and conservation action plan, IUCN/SSC Canid Specialist Group, Gland, Switzerland and Cambridge, UK.

Sokal RR, Rohlf FJ (1995) Biometry. The principles and practice of statistics in biological research, W.H. Freeman and Co, New York.

Spielman D, Brook BW, Frankham R (2004) Most species are not driven to extinction before genetic factors impact them. Proc. Natl. Acad. Sci. USA, 101, 15261-15264.

Storme V, Vanden Broeck A, Ivens B, et al. (2004) Ex-situ conservation of Black poplar in Europe: genetic diversity in nine gene bank collections and their value for nature development. Theor. Appl. Genet., 08, 969-981.

Swofford DL, Selander R (1999) BIOSYS-2: A Computer Program for the Analysis of Allelic Variation in Population 
Genetics and Biochemical Systematics (Release 2.0), University of Illinois, Urbana, Champaign, IL.

Taberlet P (1996) The use of mitochondrial DNA control region sequencing in conservation genetics In: Molecular Genetic Approaches in Conservation (eds. Smith TB, Wayne RK), pp. 125-142. Oxford University Press, New York.

Thurber JM, Peterson RO (1991) Changes in body size associated with range expansion in the coyote (Canis latrans). $J$. Mammal., 72, 750-755.

USFWS (1998) Endangered and threatened wildlife and plants: establishment of a nonessential experimental population of the Mexican gray wolf in Arizona and New Mexico. Federal Register, 63, 1752-1772.

Vilà C (1993) Aspectos morfológicos y ecológicos del lobo ibérico Canis lupus. L. PhD Thesis, Universidad de Barcelona.

Vilà C, Savolainen P, Maldonado JE, et al. (1997) Multiple and ancient origins of the domestic dog. Science, 276, 1687-1689.

Vilà C, Wayne RK (1999) Hybridization between wolves and dogs. Conserv. Biol., 13, 195-198.

Vilà C, Amorin IR, Leonard JA, Posada D, Castroviejo SJ, Petrucci-Fonseca F, Crandall A, Ellegren SH, Wayne RK
(1999) Mitochondrial DNA phylogeography and population history of the grey wolf Canis lupus. Mol. Ecol., 8, 20892103.

Vilà C, Walker C, Sundqvist AK, et al. (2003) Combined use of maternal, paternal and bi-parental genetic markers for the identification of wolf-dog hybrids. Heredity, 90, $17-24$.

Wayne RK, Jenks SM (1991) Mitochondrial-DNA analysis implying extensive hybridization of the endangered red wolf Canis-Rufus. Nature, 351, 565-568.

Wayne RK, Brown DM (2001) Hybridization and conservation of carnivores. In: Carnivore Conservation (eds. Gittleman JL, Funk SM, Macdonald D, Wayne RK), Cambridge University Press, Cambridge.

Weir BS, Cockerham CC (1984) Estimating F-statistics for the analysis of population structure. Evolution, 38, 13581370.

Wyner YM, Amato G, Desalle R (1999) Captive breeding, reintroduction, and the conservation genetics of black and white ruffed lemurs, Varecia variegata variegata. Mol. Ecol., 8, S107-S115. 